\title{
Avaliação de técnicas para a multiplicação de estacas semilenhosas de aceroleira 'Dominga' (Malpighia emarginata D.C.)
}

\author{
Evaluation of techniques for 'Dominga' acerola \\ softwood cuttings multiplication
}

\author{
Sérgio Ruffo Roberto ${ }^{1 *}$; Paulo Augusto Cicogna Paiolo²
}

\section{Resumo}

O presente trabalho teve como objetivo avaliar o efeito do tipo de substrato e do preparo de estacas no enraizamento de acerola 'Dominga' (Malpighia emarginata D.C.) produzidas em duas épocas. Foram utilizadas estacas semilenhosas de aproximadamente $12 \mathrm{~cm}$ de comprimento, pertencentes ao Banco de Germoplasma de acerola da Fazenda Escola da Universidade Estadual de Londrina. Foram estudados três tipos de substrato (vermiculita de granulometria fina, vermiculita de granulometria média e casca de arroz carbonizada) e dois tipos de preparo de estacas (com e sem lesão na base). A lesão consistiu em dois cortes opostos na porção basal das estacas de aproximadamente $1 \mathrm{~cm}$. Após o seu preparo, as estacas foram tratadas com ácido indol-butírico (AIB) na concentração de $400 \mathrm{mg} \cdot \mathrm{L}^{-1}$, através de imersão basal rápida (5 segundos) e imediatamente colocadas para enraizamento em caixas plásticas contendo os três tipos de substratos em câmara de nebulização em regime intermitente. $O$ ensaio foi realizado em duas épocas, sendo a primeira no verão e a segunda no outono. O delineamento experimental foi o inteiramente casualizado, com quatro repetições, sendo cada parcela composta por 10 estacas. Após 60 dias, foram avaliados os seguintes parâmetros: porcentagem de enraizamento; número de raízes por estaca; comprimento de raízes; porcentagem de estacas mortas e; peso de matéria fresca e seca das raízes. A partir dos dados avaliou-se o efeito dos fatores no enraizamento (substrato e preparo da estaca) através da análise de variância, e a comparação das médias foi realizada pelo teste de Tukey $(P<0,05)$. Pelos resultados obtidos, pôde-se concluir que: o substrato casca de arroz carbonizada foi o que apresentou os melhores resultados para os parâmetros avaliados; o emprego de lesão não resultou em benefícios para o enraizamento e; as estacas coletadas durante o outono apresentaram baixa porcentagem de enraizamento.

Palavras-Chave: Malpighia emarginata D.C., propagação, enraizamento.

\begin{abstract}
This research was an attempt to evaluate different types of substrate and cutting preparation for acerola cutting rooting on different seasons. Softwood cuttings of 'Dominga' acerola with $12 \mathrm{~cm}$ of length obtained from the Acerola Germoplasm Bank - Universidade Estadual de Londrina, were used in this work. It was studied three types of subtrate (vermiculite - small granules; vermiculite - medium granu-
\end{abstract}

\footnotetext{
1 Professor Adjunto. Área de Fruticultura. Universidade Estadual de Londrina. Departamento de Agronomia. Caixa Postal 6001. 86.051-990. Londrina, PR. Fone: (43) 371 4555. e-mail: sroberto@uel.br.

2 Acadêmico do Curso de Graduação em Agronomia da Universidade Estadual de Londrina. Departamento de Agronomia. Caixa Postal 6001. 86.051-990. Londrina, PR.

* Autor para correspondência.
} 
les and charred rice peel) and two types of cutting preparation (with and without basal lesion). The lesion consisted in two cuts of $1 \mathrm{~cm}$ of length on the cutting basal portion. Thus, the cuttings were treated with indole-butiric acid (400 mg. $\left.\mathrm{L}^{-1}\right)$ through basal immersion during 5 seconds and then immediatly placed in plastic boxes containing the substrates for rooting in a mist chamber system. The trial was carried out in two seasons (summer and fall). A randomized design with four replications was used as statistical model and each plot was composed by 10 cuttings. After 60 days, the following parameters were evaluated: porcentage of rooting; number of roots per cutting; roots length; percentage of dead cuttings; and fresh and dry matter roots weigth. Through these data, the effect of substrate and cutting preparation on rooting was evaluated using Tukey's multiple rang test $(P<0,05)$. It was possible to conclude that: charred rice peel substrate showed the best results for the rootings parameters; the basal lesion on cuttings did not result on rooting improvement; and the cuttings collected on fall, compared with those collected on summer, showed low porcentage of rooting.

Key-Words: Malpighia emarginata D.C., propagation, rooting.

\section{Introdução}

A acerola (Malpighia emarginata D.C.), também conhecida como cereja das Antilhas, constitui-se numa excepcional fonte natural de vitamina $\mathrm{C}$, sendo capaz de suprir as necessidades diárias de uma pessoa adulta com apenas três frutos diários (BLISKA; LEITE, 1995).

No Paraná, o cultivo da acerola teve seu início no litoral, no ano de 1983, mas somente a partir de 1988 alguns cultivos comerciais foram implantados na região Norte do Estado, incentivados por comerciantes interessados em comprar e processar a produção. No ano de 1992, devido à grande divulgação por parte da imprensa das qualidades nutricionais e com a crise das grandes culturas, houve um grande impulso para a expansão da cultura no Estado. Esta rápida expansão, realizada em grande parte por leigos, acarretou uma série de problemas, dentre os principais: formação de pomares com alta variabilidade genética, devido às mudas terem sido propagadas via semente; parte das mudas produzidas estavam infectadas por nematóides e custo de implantação elevado, devido ao alto preço das mudas (STENZEL; MOTTER; HADLICH, 1995).

A acerola pode ser propagada de forma sexuada, através de sementes e de forma assexuada ou vegetativa, por meio da enxertia ou da estaquia. Quando propagada por sementes, apresenta inconvenientes, como segregação hereditária e baixa porcentagem de germinação (25 a 30\%), atribuídas à incompatibilidade na polinização (ALVES et al., 1991).
A propagação assexuada, é mais eficiente pois fixa as características genéticas das plantas, induz a precocidade de produção e propicia uniformização dos pomares. Por esse motivo, a produção de mudas de acerola por este processo é principalmente realizada por viveiristas especializados (MARTINS; NOGUEIRA; MATTOS, 2000).

A propagação vegetativa de várias espécies frutíferas, através da estaquia, tem sido sugerida por vários autores, porém os resultados são variáveis de acordo com um grande número de fatores internos e externos. Destacam-se, como fatores internos, a condição fisiológica da planta matriz, idade da planta, tipo de estaca, época do ano para coleta, potencial genético do enraizamento, sanidade do material e balanço hormonal. Os principais fatores externos que afetam o enraizamento são principalmente, a temperatura, a luminosidade, a umidade e o tipo de substratos (HARTMANN; KESTER,1990; FACHINELLO et al., 1995).

Para a propagação vegetativa, como na estaquia, é muito comum a utilização de substratos artificiais como meio de enraizamento para as plantas. Existe no mercado uma série de materiais usado como substrato de plantas (GABRIELS; VERDONK; MEKERS, 1986), tais como vermiculita, casca de arroz carbonizada, serragem, areia, entre outros (CYRILLO et al., 1999).

No programa de melhoramento genético de acerola adaptada à região norte do Paraná desenvolvido pela Universidade Estadual de Londrina, foram 
selecionadas e lançadas algumas cultivares com características promissoras para consumo e industrialização, dentre elas a 'UEL-3 Dominga' (CARPENTIERI-PÍPOLO et al., 1998). Entretanto, pouco se sabe sobre as características da propagação vegetativa destas cultivares, do efeito de diferentes substratos, formas de preparo de estacas e época do ano no enraizamento em câmara de nebulização, o que motivou a pesquisa.

Tendo em vista estes aspectos, este trabalho teve como objetivo avaliar o efeito do tipo de substrato e do preparo de estacas no enraizamento da acerola 'Dominga' em duas épocas, no norte do Paraná, visando estabelecer métodos eficientes de multiplicação vegetativa para esta cultivar.

\section{Material e Métodos}

O experimento foi instalado no setor de propagação de mudas frutíferas do Departamento de Agronomia da Universidade Estadual de Londrina-UEL, PR.

Foram utilizadas estacas semilenhosas, retiradas da porção intermediária dos ramos das plantas da acerola 'Dominga' (Malpighia emarginata D.C.), de aproximadamente $12 \mathrm{~cm}$ de comprimento e com 6 folhas, pertencentes ao Banco de Germoplasma de acerola da Fazenda Escola da UEL. Os ramos apresentavam na época comprimento entre $40-50 \mathrm{~cm}$ e idade ao redor de 4 meses.

O preparo das estacas consistiu em um corte na porção superior da estaca logo acima de um nó e um corte logo abaixo de um nó na porção basal. Durante o preparo das estacas, estas eram dispostas provisoriamente em um recipiente com água para evitar a desidratação.

Foram estudados três tipos de substrato (vermiculita de granulometria fina, vermiculita de granulometria média e casca de arroz carbonizada) e dois tipos de preparo de estacas (com e sem lesão). As características químicas e físicas destes substratos foram descritas por Gonçalves e Benedetti (2000) e Röber (2000). A lesão consistiu em dois cortes lon- gitudinais opostos na porção basal das estacas, de aproximadamente $1 \mathrm{~cm}$ de comprimento e $2 \mathrm{~mm}$ de profundidade, que tiveram como finalidade expor o tecido cambial (FACHINELLO et al., 1995). O substrato à base de casca de arroz carbonizada foi preparado conforme descrito por Kämpf (2000).

Após o seu preparo, as estacas foram tratadas com ácido indol-butírico (AIB) na concentração de 400 mg.L.-1 (ROBERTO; PAIOLO, 2001), através de imersão rápida (5 segundos) da porção basal na solução (FACHINELLO et al., 1995), e imediatamente colocadas para enraizamento em caixas plásticas (com as dimensões $44 \times 30 \times 7 \mathrm{~cm}$ ) contendo os substratos, em câmara de nebulização com regime intermitente controlado por temporizador e válvula solenóide (GOMES et al., 2000).

A válvula foi programada para nebulizar as estacas durante 5 segundos a cada intervalo de 2 minutos. O bico nebulizador empregado (Modelo Mist DanSprinklers, Israel) apresenta vazão de $35 \mathrm{~L} /$ hora. A câmara de nebulização encontra-se inserida em uma estufa agrícola com cobertura de filme de polietileno transparente e sombrite $30 \%$.

O ensaio foi realizado em duas épocas, sendo a primeira no verão e a segunda no outono, em meados dos meses fevereiro e abril, respectivamente. $\mathrm{O}$ delineamento experimental foi o inteiramente casualizado, com quatro repetições em arranjo fatorial 3 x 2 (3 tipos de substrato e 2 tipos de preparo de estaca), sendo que cada parcela foi composta por 10 estacas.

Para o controle de doenças fúngicas, as estacas foram tratadas quinzenalmente com benomyl $1 \%$ por pulverização (FACHINELLO et al., 1995).

Após 60 dias da instalação do experimento, em cada época, foram avaliados os seguintes parâmetros: porcentagem de enraizamento; número de raízes por estaca; comprimento de raízes $(\mathrm{cm})$; porcentagem de estacas mortas; e peso de matéria seca das raízes (g) (GOMES et al., 2000).

A partir dos dados foi avaliado o efeito dos fatores (substrato e preparo da estaca) no enraizamento atra- 
vés da análise de variância, e a comparação das médias foi realizada pelo teste de Tukey a 5\% de probabilidade no aplicativo SAS (Statistical Analysis System).

\section{Resultados e Discussão}

As estacas coletadas durante o verão (primeira época) apresentaram para todos os tratamentos porcentagem de enraizamento superior a $63 \%$, chegan- do a $83,75 \%$ no substrato casca de arroz carbonizada, embora sem haver diferenças estatísticas entre si (Tabela 1). As estacas, após 60 dias de permanência na câmara de nebulização, apresentaram alta sobrevivência, não sendo constatada nenhuma estaca morta. Entretanto, nas estacas não enraizadas, não observou-se a formação de calos em sua base, indicando sua incapacidade de enraizamento após 60 dias de permanência na câmara de nebulização.

Tabela 1 - Valores médios da porcentagem de estacas enraizadas e análise de variância do efeito do substrato e do preparo de estacas coletadas no verão da acerola 'Dominga' (Malpighia emarginata D.C.). Londrina, PR. 2002.

\begin{tabular}{|c|c|c|c|c|c|}
\hline \multirow{3}{*}{ Substrato (S) } & \multicolumn{5}{|c|}{ Parâmetros } \\
\hline & \multirow{2}{*}{$\begin{array}{c}\% \text { de } \\
\text { estacas } \\
\text { enraizadas }\end{array}$} & \multirow{2}{*}{$\begin{array}{l}\text { número de } \\
\text { raízes por } \\
\text { estaca }\end{array}$} & \multirow{2}{*}{$\begin{array}{l}\text { comprimento } \\
\text { de raízes } \\
\text { (cm) }\end{array}$} & \multicolumn{2}{|c|}{ peso das raízes } \\
\hline & & & & matéria fresca & matéria seca \\
\hline $\begin{array}{l}\text { casca de arroz } \\
\text { carbonizada }\end{array}$ & $83,75 \mathrm{a}$ & $4,66 \mathrm{a}$ & $11,79 \mathrm{a}$ & $0,09 \mathrm{a}$ & $0,06 \mathrm{a}$ \\
\hline $\begin{array}{l}\text { vermiculita } \\
\text { fina }\end{array}$ & $76,25 \mathrm{a}$ & $4,45 \mathrm{a}$ & $10,70 \mathrm{a}$ & $0,06 \mathrm{a}$ & $0,04 \mathrm{a}$ \\
\hline $\begin{array}{l}\text { vermiculita } \\
\text { média }\end{array}$ & $63,75 \mathrm{a}$ & $4,85 \mathrm{a}$ & $2,57 \mathrm{~b}$ & $0,02 \mathrm{~b}$ & $0,01 \mathrm{~b}$ \\
\hline $\mathrm{F}$ & $2,15 \mathrm{~ns}$ & $0,76 \mathrm{~ns}$ & $44,63 * *$ & $15,38 * *$ & $24,92 * *$ \\
\hline \multicolumn{6}{|c|}{ Preparo da estaca (PE) } \\
\hline sem lesão & $75,83 \mathrm{a}$ & $4,76 \mathrm{a}$ & $8,69 \mathrm{a}$ & $0,07 \mathrm{a}$ & $0,04 \mathrm{a}$ \\
\hline com lesão & $73,33 \mathrm{a}$ & $4,55 \mathrm{a}$ & $80,02 \mathrm{a}$ & $0,05 \mathrm{~b}$ & $0,03 \mathrm{a}$ \\
\hline $\mathrm{F}$ & $0,10 \mathrm{~ns}$ & $0,57 \mathrm{~ns}$ & $0,59 \mathrm{~ns}$ & $4,69 *$ & $2,01 \mathrm{~ns}$ \\
\hline F (Int. S x PE) & $1,71 \mathrm{~ns}$ & $13,20 * *$ & $5,68 *$ & $3,94 *$ & $7,51 * *$ \\
\hline C.V. $(\%)$ & 26,10 & 14,11 & 25,53 & 45,42 & 37,25 \\
\hline
\end{tabular}

Médias seguidas de mesma letra nas colunas não diferem entre si pelo teste de Tukey $(P<0,05)$.

ns: não significativo.

*: significativo $(P<0,05)$.

**: significativo $(P<0,01)$.

Não observou-se interação significativa entre os fatores (substrato e preparo das estacas) apenas para a porcentagem de estacas enraizadas, mostrando que estes fatores agem de forma independente para este parâmetro. Para os demais, a interação foi significativa, sendo então realizado o desdobramento dos graus de liberdade da interação para análise dos parâmetros (Tabela 2). 
Tabela 2 - Interação entre o substrato e o preparo de estacas, coletadas no verão, em relação ao número de raízes por estaca, comprimento de raízes $(\mathrm{cm})$ e peso da matéria seca de raízes $(\mathrm{g})$ da acerola 'Dominga' (Malpighia emarginata D.C.). Londrina, PR. 2002.

\section{Preparo da estaca}

\begin{tabular}{llccc} 
& \multicolumn{1}{c}{ Substrato } & Sem lesão & com lesão & $\mathrm{F}$ \\
\cline { 3 - 4 } número de & casca de arroz carbonizada & $5,47 \mathrm{Aa}$ & $3,86 \mathrm{Bb}$ & $12,05^{* *}$ \\
raízes por & vermiculita fina & $4,78 \mathrm{Aab}$ & $4,12 \mathrm{Ab}$ & $2,04 \mathrm{~ns}$ \\
estaca & vermiculita média & $4,02 \mathrm{Bb}$ & $5,69 \mathrm{Aa}$ & $12,88^{* *}$ \\
\hline $\mathrm{F}$ & & $4,87 *$ & $9,08^{* *}$ & \\
\hline comprimento & casca de arroz carbonizada & $14,05 \mathrm{Aa}$ & $9,53 \mathrm{Ba}$ & $8,96^{* *}$ \\
de raízes & vermiculita fina & $9,40 \mathrm{Ab}$ & $12,01 \mathrm{Aa}$ & $2,99 \mathrm{~ns}$ \\
$(\mathrm{~cm})$ & vermiculita média & $2,62 \mathrm{Ac}$ & $2,52 \mathrm{Ab}$ & $0,004 \mathrm{~ns}$ \\
\hline $\mathrm{F}$ & & $29,05^{* *}$ & $21,26^{* *}$ & \\
\hline peso de raízes & casca de arroz carbonizada & $0,12 \mathrm{Aa}$ & $0,06 \mathrm{Bab}$ & $12,14^{* *}$ \\
matéria fresca & vermiculita fina & $0,06 \mathrm{Ab}$ & $0,07 \mathrm{Aa}$ & $0,09 \mathrm{~ns}$ \\
(g) & vermiculita média & $0,02 \mathrm{Ab}$ & $0,01 \mathrm{Ab}$ & $0,33 \mathrm{~ns}$ \\
\hline $\mathrm{F}$ & & & \\
\hline peso de raízes & casca de arroz carbonizada & $0,08 \mathrm{Aa}$ & $0,04 \mathrm{Ba}$ & $15,56 * *$ \\
matéria seca & vermiculita fina & $0,03 \mathrm{Ab}$ & $0,04 \mathrm{Aa}$ & $1,38 \mathrm{~ns}$ \\
$(\mathrm{~g})$ & vermiculita média & $0,01 \mathrm{Ac}$ & $0,01 \mathrm{Ab}$ & $0,10 \mathrm{~ns}$ \\
\hline $\mathrm{F}$ & & $25,28^{* *}$ & $7,15^{* *}$ & \\
\hline
\end{tabular}

Letras iguais maiúsculas nas linhas e minúsculas nas colunas, não diferem entre si pelo teste de Tukey $(P<0,05)$. ns: não significativo.

*: significativo $(P<0,05)$.

**: significativo $(P<0,01)$.

Em relação ao número de raízes por estaca, não foram observadas diferenças significativas somente para o substrato vermiculita fina. Para o substrato casca de arroz carbonizada as maiores médias foram obtidas quando empregaram-se estacas sem lesão, mostrando que para este substrato, esta técnica resultou em uma redução do número de raízes.

Para o substrato vermiculita média a realização da lesão favoreceu um maior número de raízes emitidas, indicando que as características deste substrato exerceu influência sobre esta característica, porém, deve ser considerado que o comprimento e o peso seco de raízes foi significativamente inferior em relação aos demais substratos, ou seja, mesmo com maior número de raízes emitidas, estas eram de qualitativamente inferiores. Estacas preparadas sem lesão apresentaram maior número de raízes no substrato casca de arroz carbonizada, que foi significativamente superior a vermiculita média. Para estacas com lesão, a maior média foi obtida para vermiculita média (Tabela 2).

Segundo Fachinello et al. (1995), a realização da lesão nas estacas pode promover a formação de raízes em espécies que apresentam algum tipo de barreira mecânica à emissão de raízes, especialmente as estacas que apresentam madeira velha na sua base. Entretanto, a realização da lesão nem sempre apresenta vantagens para o enraizamento, conforme demonstraram Nachtigal e Pereira (2000) que avaliaram esta técnica visando promover maior enraizamento do porta-enxerto de pessegueiro 'Okinawa' em diferentes substratos em câmara de nebulização.

Considerando-se o comprimento de raízes, observou-se diferenças significativas $(P<0,01)$ somente 
entre o preparo das estacas para o substrato casca de arroz carbonizada, onde estacas sem lesão resultaram na maior média observada, indicando que esta técnica resulta em menores médias para este parâmetro avaliado. Para estacas que não sofreram lesão na base, as maiores médias foram observadas para o substrato casca de arroz carbonizada, vermiculita fina e vermiculita média, em ordem decrescente, apresentando diferenças significativas $(P<0,01)$ entre si. Para estacas preparadas com lesão, a menor média obtida foi para o substrato vermiculita média, diferindo estatisticamente dos demais.

Considerando-se o peso das raízes (matéria seca), somente observou-se diferença significativa $(P<0,01)$ para casca de arroz carbonizada onde as estacas sem lesão apresentaram maior média que as com lesão, mostrando que esta forma de preparo, resulta em um maior volume de sistema radicular para a cultivar de acerola estudada. Para estacas sem lesão as maiores médias foram obtidas para casca de arroz carbonizada, que diferiu significativamente $(P<0,01)$ da vermiculita média. Para estacas com lesão as maiores médias foram observadas para casca de arroz carbonizada e vermiculita fina, resultando em maior massa de raízes.

O maior desenvolvimento radicular das estacas observado no substrato casca de arroz carbonizada atribui-se, provavelmente, à maior drenagem de água que este substrato confere, já que a sua capacidade máxima de retenção de água é menor que a metade da capacidade máxima de retenção de água do substrato vermiculita fina, conforme descrito por Gonçalves e Benedetti (2000).

Para as estacas coletadas durante o outono (segunda época), observou-se que a porcentagem de enraizamento foi muito baixa (inferior a 7,5\%), sendo estas de reduzido número de raízes e também de reduzido comprimento (Tabela 3), não permitindo que fossem avaliados os dados relativos ao peso de raízes (matéria seca). Contudo, não foi observada para esta época mortalidade das estacas, sendo que estas se mantiveram com alta retenção foliar durante toda o período em que foram mantidas na câmara de nebulização. Desta forma, pôde-se constatar que o enraizamento desta cultivar, nesta época do ano apresenta grandes limitações, não sendo viável sua aplicação neste período.

Tabela 3 - Valores médios da porcentagem de estacas enraizadas, número de raízes por estacas, comprimento de raízes $(\mathrm{cm})$ e análise de variância do efeito do substrato e do preparo de estacas coletadas no outono da acerola 'Dominga' (Malpighia emarginata D.C.). Londrina, PR. 2002.

\begin{tabular}{lccc}
\hline \multirow{2}{*}{ Substrato (S) } & \multicolumn{3}{c}{ Parâmetros } \\
\cline { 2 - 4 } & $\begin{array}{c}\text { \% de estacas } \\
\text { enraizadas }\end{array}$ & $\begin{array}{c}\text { número de raízes por } \\
\text { estaca }\end{array}$ & $\begin{array}{c}\text { comprimento de } \\
\text { raízes }(\mathrm{cm})\end{array}$ \\
\hline casca de arroz carbonizada & $7,50^{\mathrm{z}}$ & 1,00 & 1,25 \\
Vermiculita fina & 1,25 & 0,12 & 0,06 \\
Vermiculita média & 6,25 & 1,00 & 0,29 \\
\hline F & $2,42 \mathrm{~ns}$ & $2,58 \mathrm{~ns}$ & $2,65 \mathrm{~ns}$ \\
\hline Preparo da estaca (PE) & & & 0,58 \\
\hline sem lesão & 2,50 & 0,42 & 0,48 \\
com lesão & 7,50 & 1,00 & $0,05 \mathrm{~ns}$ \\
\hline F & $4,15 \mathrm{~ns}$ & $2,58 \mathrm{~ns}$ & $0,38 \mathrm{~ns}$ \\
\hline F (Int. S x PE) & $0,35 \mathrm{~ns}$ & $0,37 \mathrm{~ns}$ & 40,99 \\
C.V. (\%) & 71,57 & 37,19 & \\
\hline
\end{tabular}

${ }^{\mathrm{z}}$ :Dados originais. Para fins de análise estatística os dados foram transformados em arcsen $\sqrt{\mathrm{x}}+0,5$. ns: não significativo. 
Os resultados obtidos mostram que existe influência da época do ano no enraizamento de estacas semilenhosas de acerola 'Dominga', confirmando os dados observados por Rodriguez (1998), bem como existe influência do tipo de substrato nesta característica de propagação vegetativa. A alta porcentagem de enraizamento observada na primeira época pode ser atribuída a fatores como a condição fisiológica apresentada pela planta matriz. Segundo Fachinello et al. (1995), esta é representada por características internas como o conteúdo de água, teor de reservas e de nutrientes, possibilitando o fornecimento de estacas semilenhosas favoráveis ao enraizamento, bem como pelas condições climáticas desse período. A baixa porcentagem de enraizamento na segunda época pode ser explicada pelo estádio vegetativo avançado da planta matriz, a qual forneceu estacas com maior grau de lignificação, as quais, segundo Hartmann e Kester (1990), são desfavoráveis ao enraizamento, juntamente com o fator externo temperatura, que se apresentou mais baixa que na primeira época

O maior enraizamento das estacas no verão observado neste trabalho está de acordo com os resultados obtidos por Leonel et al. (1991) e Bezerra et al. (1991), os quais mostraram para outras cultivares de acerola que nesta estação do ano ocorre maior enraizamento de estacas, enquanto no outono este torna-se dificultado. Porém, destacam-se as observações realizadas por Gomes et al. (2000) que relatam que estes resultados são variáveis em função das características genéticas de cada cultivar.

\section{Conclusões}

Através dos resultados obtidos nas condições em que foi conduzido o presente ensaio de propagação da acerola 'Dominga' por estacas semilenhosas, conclui-se que:

a) não há diferenças significativas entre os substratos testados quanto à porcentagem de estacas enraizadas. b) os substratos casca de arroz carbonizada e vermiculita fina, propiciam maior comprimento e peso seco de raízes.

c) o emprego de lesão na base da estaca não resulta em melhorias nos parâmetros de enraizamento de estacas.

d) estacas coletadas e preparadas no verão apresentam ótimo padrão de enraizamento, enquanto que as coletadas no outono não apresentam bom desempenho.

\section{Referências}

ALVES, R. E. et al. Contribuição ao estudo da cultura da acerola. Revista Brasileira de Fruticultura, Cruz das Almas, v.13, n.2, p.19-26, 1991.

BEZERRA, J. E. F. et al. Efeito do tamanho das estacas herbáceas e do ácido indol-butírico no enraizamento da acerola (Malpighia glabra L.) em duas épocas de estaquia. Revista Brasileira de Fruticultura, Cruz das Almas, v.13, n.3, p.157-163, 1991.

BLISKA, F. M. M.; LEITE, R. S. S. F. Aspectos econômicos e de mercado. In: SÃO JOSÉ, A. R.; ALVES, R. E. Acerola no Brasil, Produção e Mercado. Vitória da Conquista: DFZ/UESB, 1995. p.107-123.

CARPENTIERI-PÍPOLO, V. et al. Novos cultivares de acerola: UEL-3 Dominga, UEL-4 Lígia, UEL-5 Natália. In: CONGRESSO BRASILEIRO DE FRUTICULTURA, 15. 1998, Poços de Caldas. Resumos... Poços de Caldas: Sociedade Brasileira de Fruticultura, 1998.

CYRILLO, F. L. L. et al. Multiplicação de porta-enxertos de videira por meio de estacas semilenhosas, em dois substratos, conduzidos em câmara de nebulização. Revista Brasileira de Fruticultura, Jaboticabal, v.21, n.3, p.266-268, 1999.

FACHINELLO, J. C. et al. Propagação de plantas frutíferas de clima temperado. Pelotas: UFPEL, 1995.

GABRIELS, R.; VERDONK, O.; MEKERS, O. Substrate requirements for pot plants in recirculating waters culture. Acta Horticulturae, The Hauge, v.178, p.93-99, 1986.

GOMES, J. E.et al. Enraizamento de estacas herbáceas de genótipos de acerola em câmara de nebulização intermitente tratadas com ácido indolbutírico em duas épocas. Revista Brasileira de Fruticultura, Jaboticabal, v.22, n.3, p.407-412, 2000. 
GONÇALVES, J. L. M.; BENEDETTI, V. Nutrição e fertilização florestal. Piracicaba: IPEF, 2000.

HARTMANN, H. T.; KESTER, D. E. Propagación de plantas: princípios y practicas. México: Compañia Editorial Continental, 1990.

KÄMPF, A. N. Produção comercial de plantas ornamentais. Guaíba: Agropecuária, 2000.

LEONEL, S. et al. Enraizamento de estacas de acerola (Malpighia glabra, Linn.). Revista Brasileira de Fruticultura, Cruz das Almas, v.13, n.3, p.213-217, 1991.

MARTINS, A. B. G.; NOGUEIRA, J. A. D.; MATTOS, L. P. B. Fatores que afetam a propagação da aceroleira (Malpighia glabra L.) por estaquia herbácea. In: CONGRESSO BRASILEIRO DE FRUTICULTURA, 16., 2000, Fortaleza. Anais... Fortaleza, 2000. p.48. CDROM.

NACHTIGAL, J. C., PEREIRA, F.M. Propagação do pessegueiro (Prunus persica (L.) Batsch) cultivar Okinawa por meio de estacas herbáceas em câmara de nebulização. Revista Brasileira de Fruticultura, Cruz das Almas, v.22, n.2,p.208-212, 2000.
RÖBER, R. Substratos hortícolas: possibilidades e limites de sua composição e uso; exemplos da pesquisa, da industrústia e do consumo. In: KÄMPF, A. N.; FERMINO, M. H. Substrato para plantas, a base da produção vegetal em recipientes. Porto Alegre: Genesis, 2000. p.123-138.

ROBERTO, S. R.; PAIOLO, P. A. C. Efeito do ácido indolbutírico no enraizamento de estacas semilenhosas de acerola 'Dominga' (Malpighia emarginata D.C.). In: MOSTRA ACADÊMICA DE TRABALHOS DE AGRONOMIA, 5., Londrina, 2001. Resumos... Londrina: Universidade Estadual de Londrina. 2001. p.83.

RODRIGUEZ, P. B. N. Efeito da época do ano no enraizamento de estacas de acerola (Malpighia glabra). 1998. Trabalho de Conclusão (Curso em Agronomia) Universidade Estadual de Londrina, Londrina.

STENZEL, N. M. C; MOTTER, A. A.; HADLICH, E. Cultura da acerola no Estado do Paraná - pesquisa e extensão. In: SÃO JOSÉ, A. R.; ALVES, R. E. Acerola no Brasil, produção e mercado. Vitória da Conquista: DFZ/ UESB, 1995, p.130-132. 